\title{
A presença de agentes intermediadores na formação de redes interorganizacionais: uma análise sob a perspectiva temporal ${ }^{1}$
}

\author{
The presence of intermediate agents in the establishment of interorganizational networks: \\ an analysis grounded on a temporal perspective
}

\author{
Julio Araujo Carneiro da Cunha ${ }^{2}$ \\ João Luiz Passador ${ }^{3}$ \\ Cláudia Souza Passador ${ }^{4}$
}

\begin{abstract}
"...tempo é um tecido invisível em que se pode bordar tudo, uma flor, um pássaro, uma dama, um castelo, um túmulo. Também se pode bordar nada. Nada em cima de invisível é a mais sutil obra deste mundo, e acaso do outro." (Machado de Assis)
\end{abstract}

\section{Resumo}

Nos estudos sobre redes interorganizacionais, existem esforços focados em entender a formação de redes, assunto esse que gera interesse dos formuladores de políticas públicas já que se busca no associativismo promovido pelo Estado e pelas iniciativas privadas, substância para impulsionar o desenvolvimento local. Diante disso, o objetivo do estudo foi verificar, por meio da formalização do Arranjo Produtivo Local (APL) de calçados de Birigüi (SP), se a presença desses agentes é essencial para a formação da rede interorganizacional. Como sustentações teóricas foram abordadas: a evolução temporal das redes; a Teoria Institucional aplicada às redes interorganizacionais; o capital social presente nos laços de relacionamento; a presença de agentes intermediários como coordenadores na governança das redes. A estratégia de pesquisa adotada baseou-se em entrevistas com $32 \%$ dos gestores das empresas que participavam formalmente do APL e com uma gestora do agente intermediador, além de observação e análises de

Artigo submetido em 09 de dezembro de 2010 e aceito para publicação em 15 de abril de 2011.

${ }^{1}$ (a) Esse artigo é resultado das discussões oriundas da linha de pesquisa sobre Redes Interorganizacionais do grupo de pesquisa GPublic (Centro de Estudos em Gestão e Políticas Públicas Contemporâneas) da FEA-RP / USP, tal como o artigo intitulado "Recomendações e apontamentos para categorizações em pesquisas sobre redes interorganizacionais", publicado, nessa mesma revista, no volume IX, Edição Especial. A perspectiva temporal orientadora do método de pesquisa aqui construído foi abordada nesse artigo anteriormente publicado, no momento em que ele comenta a importância do contexto sociocultural das redes interorganizacionais.

(b) Uma versão preliminar deste artigo foi publicada no IV Encontro de Administração Pública e Governança da ANPAD - ENAPG realizado em Vitória - ES no período de 28 a 30 de novembro de 2010.

2 Doutor em Administração de Empresas pela Fundação Getulio Vargas / EAESP. Endereço: EAESP/FGV - Escola de Administração de Empresas de São Paulo, Avenida Nove de Julho, 2029, Bela Vista, CEP 01313-902, São Paulo - SP, Brasil. E-mail: juliocunha@yahoo.com

${ }^{3}$ Doutor em Administração de Empresas pela Fundação Getulio Vargas / EAESP; Professor doutor do Departamento de Administração da Universidade de São Paulo / FEA-RP. Endereço: FEA-RP / USP - Faculdade de Economia, Administração e Contabilidade Departamento de Administração, Avenida dos Bandeirantes, 3900, Monte Alegre, CEP 14040-900, Ribeirão Preto - SP, Brasil. Email: ilpassador@usp.br

4 Doutora em Educação pela Universidade de São Paulo / FEUSP; Professora doutora do Departamento de Administração da Universidade de São Paulo / FEA-RP. Endereço: Avenida dos Bandeirantes, 3900, Monte Alegre, CEP 14040-902, Ribeirão Preto SP, Brasil. E-mail: cspassador@usp.br 
pesquisas prévias sobre a industrialização de Birigüi. Como resultados verificou-se haver um legado regional que sustenta uma base de know-how para a industrialização de calçados. No entanto, percebeu-se que os interesses dos participantes do APL eram predominantemente comerciais, sem haver um nível de capital social e de institucionalização desenvolvidos a ponto de se criarem, de forma legítima, associações provenientes de vontades das próprias organizações. Sem esse ambiente institucional fortemente construído na região, não se verificou um racional claro para o associativismo, havendo a percepção de que os ganhos oriundos da participação na rede são futuros. Concluiu-se que a coordenação realizada por um agente intermediador tem poder de articulação limitado na formação de redes interorganizacionais se não existir uma institucionalização prévia que envolva, principalmente, valores e normas de capital social. Sem esses pré-requisitos, o agente intermediador pode acabar por ter funções de governança para ações assessórias da rede.

Palavras-chave: Agentes intermediadores. Redes interorganizacionais. APL. Governança de redes.

\section{Abstract}

There are academic efforts to understand the formation of networks in the interorganizational research agenda, a subject that attracts the interest of policy makers since they seek through associative initiatives promoted by the State or through private agents, substance to promote local development. Based on this, the objective of this study is to verify, through the formation of the shoe cluster in Birigüi, São Paulo State, whether the presence of these agents is essential for cluster formation. The theoretical foundations are the temporal evolution of networks, the Institutional Theory applied to interorganizational networks, social capital embedded in relational ties and the presence of intermediate agents as coordinators in network governance. The research strategy adopted was based on interviews with $32 \%$ of the managers of an enterprise that formally joined the cluster and with a manager from the intermediate agent, in addition to the researcher's observation and analysis of previous studies of Birigüi's industry. The results verified the existence of a regional legacy that supports a local know-how knowledge base for shoe manufacturing. However, it was perceived that the interests of participants in the cluster were mainly focused on commercial issues, without the development of an adequate level of social capital and institutionalization to legitimately create an association as a result of the organizations' own will. Without this strong institutional environment in the region, a clear rational explanation for associative initiatives could not be found. The perception was that gains from network participation are expected for the future. It was concluded that the coordination done by an intermediate agent has limited articulated power in the formation of an interorganizational network when there is no previous institutional formation that involves, mainly, social capital values and norms. Without these pre-requirements, the intermediate agent may end up with governance functions for the network's accessory actions.

Keywords: Intermediate agents. Interorganizational networks. Cluster. Network governance.

\section{Introdução e contextualização do problema de pesquisa}

Por mais que alguns estudos pontuais sobre os ganhos provenientes de relações interorganizacionais existissem no início do século XX (e.g. MARSHALL, 1920), somente a partir do final da Segunda Guerra Mundial os estudos sobre as vantagens das relações externas passaram a ganhar uma linha de pesquisa estruturada com embasamento sociológico na academia. No entanto, os primeiros esforços dessa fase focaram-se na preocupação eminente com os retornos que os indivíduos poderiam obter por meio de suas redes de relacionamentos (e.g. SIMMEL, 1955; GRANOVETTER, 1973). Com a evolução desses estudos, essa perspectiva de vantagens provenientes da associação entre indivíduos passou a ser aplicada às organizações. A partir da década de 1980, emergiram-se em quantidade considerável estudos com embasamento econômico que focavam a organização e suas associações com outras organizações (SMITHDOERR e POWELL, 2004), tal como estudos com embasamento social sobre essas redes de relacionamento de organizações (BORGATTI e FOSTER, 2003). Ao longo desses 30 anos de pesquisas dedicadas às organizações e suas associações, um dos assuntos discutidos foi a forma pela qual as redes interorganizacionais evoluem e se desenvolvem. Estudos analisaram diversas etapas de evolução das redes 
interorganizacionais e de alianças entre organizações: a formação das redes (e.g. WALKER, KOGUT e SHAN, 1997; EBERS, 1999; PASSADOR e CARNEIRO DA CUNHA, 2008); a evolução e o desenvolvimento das redes (e.g. BUTLER e HANSEN, 1991; DOZ, 1996; RING, 2000); e a dissolução delas (e.g. LEVINTHAL e FICHMAN, 1988; POWELL, KOGUT e SMITH-DOERR, 1996; TÖRNROOS, 2004). No entanto, o palco de discussões sobre a evolução das redes não está esgotado, havendo ainda oportunidades de estudo sobre a evolução das estruturas de redes e temas importantes para o desenvolvimento do conhecimento da área (KNOBEN, OERLEMANS e RUTTEN, 2006).

Um dos pontos importantes para a discussão na área é a gênese das alianças e redes interorganizacionais e os elementos propulsores dessa união. O tema é de interesse tanto para os práticos quanto para os acadêmicos. Em relação aos práticos, existe o interesse de entender quais são de fato os elementos que favoreçam ao sucesso de alianças estratégicas e também há os interesses dos formuladores de políticas públicas que buscam no associativismo, em especial, de pequenas e médias empresas, substância para impulsionar o desenvolvimento local. Academicamente, o interesse reside na compreensão de variáveis fundamentais e de grande influência para a formação de redes interorganizacionais, que ainda não ganharam uma linha de pensamento homogênea e amplamente aceita entre os estudiosos.

O grande embate da formação de redes interorganizacionais reside quando se percebe que, por um lado, a formação de redes interorganizacionais depende de antecedentes sociais capazes de gerar a imersão institucional dos seus membros (GRANDORI e SODA, 1995); por outro, podem existir experiências em que se tenta atingir esse nível de imersão institucional por meio de uma institucionalização coercitiva. Traz-se à tona a discussão da real necessidade da existência de antecedentes sociais que são capazes de fomentar a associação de organizações. A partir disso, põe-se em questão se as organizações intermediadoras de associações interorganizacionais são preteríveis para a formação de uma rede entre organizações. Ou ao menos, se elas têm efeito catalisador dessas relações para construção do espírito de igualdade e cooperação, dado a existência prévia de semelhança institucional dentre os participantes de redes interorganizacionais.

Paralelamente à necessidade de se compreender o papel desses agentes intermediadores, os cientistas sociais comumente não estão preocupados em entender como indivíduos ou agentes desenvolvem e administram a estrutura da rede, mas sim em questões de formas e padrões sociais das relações (LOWRIE e McKNIGHT, 2004). Daí a importância em se estabelecer numa discussão de cunho social a questão dos agentes envolvidos com as redes interorganizacionais, a fim de proporcionar uma perspectiva multiparadigmática e multidisciplinar para a abordagem das redes. ${ }^{5}$ Unir essas duas perspectivas num mesmo plano pode responder perguntas relevantes para os estudos da área, como: A presença de políticas públicas que incentivam a formação de redes interorganizacionais por meio da presença de agentes intermediadores pode fomentar o funcionamento da rede, ou essa união depende de valores socialmente construídos entre os membros da rede que ultrapassam as possibilidades de atuação desses agentes? É eminente a necessidade de responder essa pergunta de pesquisa por meio de experiências empíricas que possam servir de respaldo para uma análise minuciosa. Principalmente quando as experiências de redes já acompanhadas por acadêmicos

\footnotetext{
${ }^{5}$ Gioia e Pitre (1990) alegam que as pesquisas do campo das organizações podem assumir em suas abordagens perspectivas multiparadigmáticas entre as teorias tradicionais e as teorias alternativas. Dessa forma, os autores acreditam que se consiga assumir especificidades teóricas que não estão contidas nas perspectivas tradicionais e assim, se consegue adquirir uma visão mais compreensível dos fenômenos organizacionais. Essa proposta pode ser aplicável também ao campo dos estudos das relações interorganizacionais. Ainda que cada um dos paradigmas propostos pelos acadêmicos para se justificar a formação de alianças interorganizacionais sejam úteis, eles ainda são limitados para capturar todas as complexidades envolvidas neste processo de formação (BARRINGER e HARRISON, 2000). A análise de redes sociais envolve um campo de estudo interdisciplinar, com um longo histórico de inputs provenientes da sociologia, antropologia, estatística, matemática, ciência da informação, educação, psicologia, dentre outras (VAN DUJIN e VERMUNT, 2006). Por isso, Passador e Carneiro da Cunha (2008, p.68) alegam que: "o entrelaçamento de entre as teorias vigentes torna-se fundamental para se compreender de forma mais abrangente e completa as redes interorganizacionais e suas respectivas complexidades".
} 
ainda deixam lacunas de temas que carecem de confirmações empíricas (JONES, HESTERLY e BORGATTI, 1997; HOANG e ANTONCIC, 2003).

Diante do exposto, o presente estudo tem como objetivo identificar, por meio da experiência da formalização do Arranjo Produtivo Local (APL) de calçados de Birigüi (SP), se a presença de um agente intermediador que articula essa união é preterível para a formação da rede. Pretende-se com isso estipular qual o real papel de políticas públicas que buscam incentivar o desenvolvimento econômico local por meio da formação das redes interorganizacionais capitaneadas por um agente intermediário.

\section{A perspectiva temporal nas redes interorganizacionais}

A discussão sobre o tempo nas ciências naturais, em especial, na Física, é bastante complexa e envolve conceitos abstratos, que consideram o tempo como uma invenção humana capaz de ordenar os fenômenos dentro de uma linearidade do fluxo passado-presente-futuro. Nesse sentido, o tempo é relativo ao movimento médio da matéria, sendo ele o único responsável por mudanças (GÖDEL, 1949). Munido dessa conceituação clássica de tempo preconizada por Albert Einstein, e apoiando-se na percepção de Capra (1982) de que a noção das ciências naturais pode ter compatibilidade com as demais ciências, aplica-se esse conceito de temporalidade para o caso das organizações estruturadas em rede. ${ }^{6}$ As relações provenientes das redes não são, portanto, baseadas apenas em atores, mas também em relações com o tempo, em que a formação de redes carrega ranços de experiências passadas dos participantes e também criam expectativas antecipadas do futuro (TÖRNROOS, 2004). Portanto, se aceita a noção relativa de tempo em que o passado, presente e futuro estão interligados e na qual o tempo não é congruente ao "tempo do relógio", mas sim à experiência de eventos sentidos e vividos pelos membros da rede (HEDAA e TÖRNROOS, 2008).

Logo, a sucessão de eventos de uma rede não significa, necessariamente, que ela tem estruturas sociais desenvolvidas. Sua evolução temporal depende das suas experiências adquiridas e, consequentemente, da intensidade dos laços criados entre os membros da rede. Isso implica que a temporalidade envolve a intensidade com que ocorrem as ligações entre os membros da rede. Dessa forma, as redes interorganizacionais carregam em seu histórico um ranço de relações sociais e econômicas que sustentam e intermedeiam suas relações, formando um legado que as diferenciam das demais em termos de competitividades e estrutura social.

Diante disso, essa conceituação traz um embate nos processos formais de evolução das redes interorganizacionais. Existe uma evolução burocrática e formal das redes, que envolve desde a negociação de sua formação institucional até a decisão por sua descontinuidade comercial. Ring (2000) definiu existir algumas atividades-chave para os participantes de redes interorganizacionais ao longo da evolução da rede conforme o Quadro a seguir:

\footnotetext{
${ }^{6}$ A conceituação de rede aqui suportada é aquela que pode ser sintetizada no que Suzigan, Furtado, Garcia et al. (2003, p.2) caracterizam como Arranjo Produtivo Local (APL): "Sistemas locais de produção podem ter variadas caracterizações conforme sua história, evolução, organização institucional, contextos sociais e culturais nos quais se inserem, estrutura produtiva, organização industrial, formas de governança, logística, associativismo, cooperação entre agentes, formas de aprendizado e grau de disseminação do conhecimento especializado local."
} 
Quadro 1

Processos de troca na evolução das alianças estratégicas

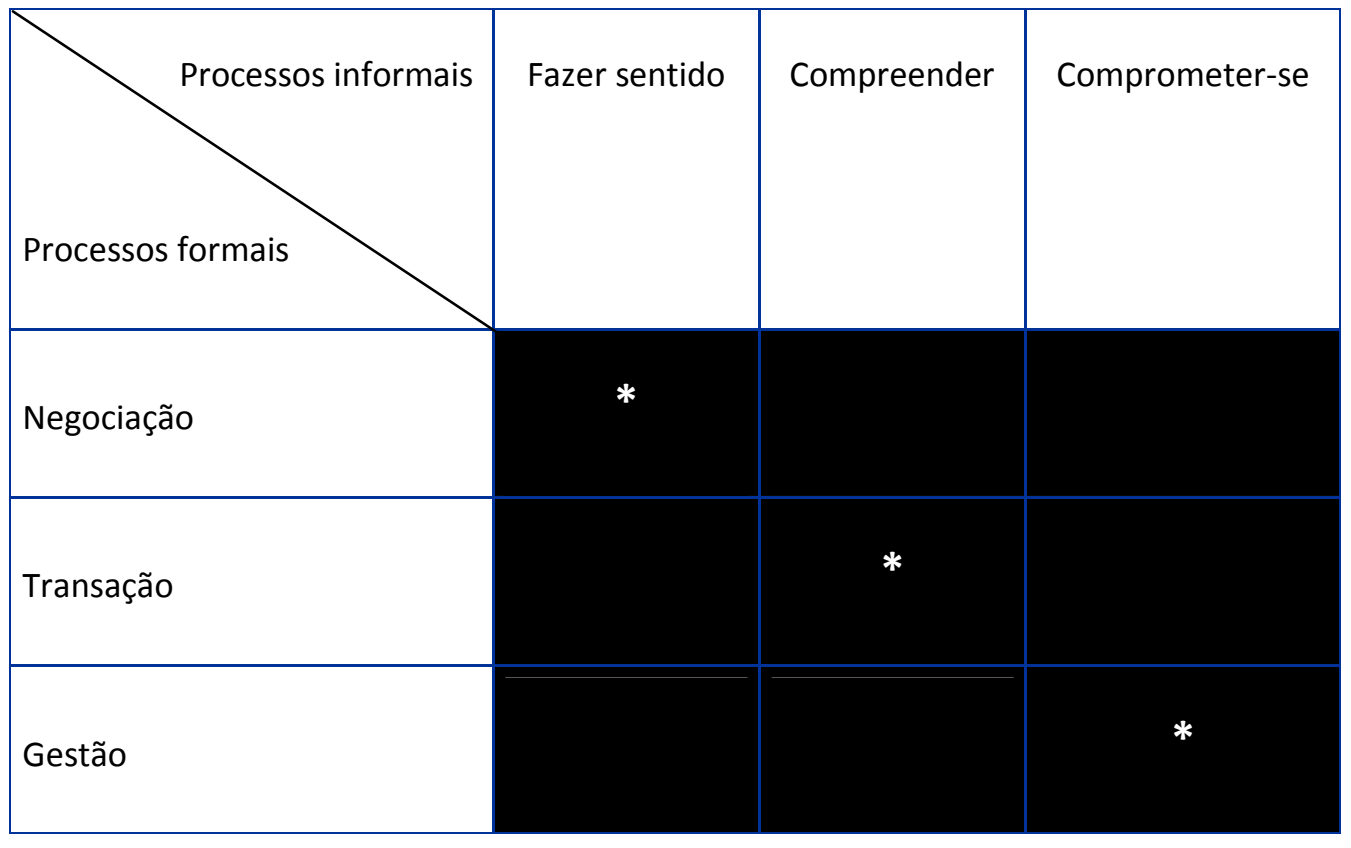

Fonte: Adaptado de Ring, 2000, p.155.

Deve-se ter em mente que existe, em paralelo, uma evolução informal das relações dos membros da rede. No entanto, nem sempre a intersecção entre essas duas dimensões segue a evolução natural de um contrato social. Há, por vezes, a imposição de formalizações e burocracias sem que exista um desenvolvimento prévio de caráter social e implícito capaz de sustentar as normas e processos estabelecidos de maneira formal. Isso envolve a negociação e a transação efetiva na formação da rede com os processos informais, que envolvem a compreensão do funcionamento da rede e de seus relacionamentos, tal como a lógica de aceitação e validação dos membros da rede para participar dela. Ou seja, a formação de uma rede interorganizacional envolve desde a lógica do parceiro em aceitar e aprender elementos oriundos da participação da rede, que se representam desde a negociação até a intermediação contratual propriamente dita que formaliza o início do funcionamento da rede.

\section{Teoria Institucional na formação das redes interorganizacionais}

Diante desse embate entre o que é formalizado nas relações entre organizações e o que é instituído na camada implícita, surge a discussão embasada na Teoria Institucional. De acordo com Giddens (1984), as institucionalizações estabelecidas socialmente são as características mais resistentes da vida social, capazes de dar solidez aos sistemas sociais através do tempo e espaço. Por isso a importância da Teoria Institucional para se compreender o fenômeno das redes interorganizacionais. Ela parte do princípio de que forças normativas influenciam as organizações, sendo elas provenientes de agentes externos ou mesmo da própria organização (ZUCKER, 1987). Aplicando isso ao ambiente de rede, as organizações participantes são influenciadas por essas pressões de cunho social, normativo e de valores. A rede interorganizacional é, portanto, um ambiente institucional que carrega em si características histórico-sociais construídas durante sua evolução. 
Ao se falar nessas relações, não se refere somente às díades de relacionamento entre organizações, mas sim de um sistema social que envolve uma expansão de conceito para uma perspectiva maior, de constelação, tal como propõem Das e Teng (2002). Todas essas relações têm em sua estrutura um histórico de trocas entre elas e, consequentemente, a existência de institucionalizações entre elas. A socialização prévia entre os participantes da rede trazem consigo, mesmo que numa dimensão informal, o estabelecimento das primeiras institucionalizações entre as organizações. Não obstante, em decorrência dessa existência de formação institucional entre os membros de uma rede local, Gulati e Gargiulo (1999) hipotetizaram que alianças prévias entre organizações tendem a favorecer e a aumentar a probabilidade de haver uma relação entre eles no futuro. Portanto, cria-se um ambiente de colaboração que não apenas fortalece as relações entre as organizações, mas que estimula a formação da rede, independente de uma iniciativa de formalização dessas alianças.

Com o estabelecimento desse ranço histórico na rede, Scott (1995) entende que, quando esses sistemas sociais interpretam e percebem a presença de leis sociais, os elementos institucionais ganham relevância para fixar esses acordos, mesmo que eles estejam ainda na dimensão dos valores e no nível informal. Dessa forma, uma rede interorganizacional pode atuar em diferentes graus, desde a relação de conivência e cooperação entre as partes até relação puramente contratual (GAJDA, 2004). Ou seja, sua maturidade leva a uma complexidade maior, o que requer aparatos legais para assegurar comportamentos oportunistas dentro da rede. Quanto mais evoluída e complexa for a aliança estratégica, maior será o grau de formalização exigido para intermediar as relações entre as organizações (MEYER e ROWAN, 1977). Forma-se então um tecido de relações históricas da rede, carregado de experiências compartilhadas nas múltiplas relações existentes, do qual se cria um ambiente institucional influente sobre os membros associados à rede (ROWLEY, 1997). Diante disso, é importante ressaltar que esse ambiente social que influencia as organizações pertencentes à rede é carregado de valores e normas institucionalmente aceitas que são decisivas para o comportamento e na tomada de decisões dos membros da rede. Esses valores e normas não apenas vão ser influentes nas organizações, mas também ditarão as normas de conduta dentro da rede interorganizacional.

Isso significa que a estruturação de normas e leis formalizadas entre os membros de redes é mais legítima quando resultante de um histórico de relações sociais. É menos provável, porquanto menos legítimo, o nascimento de sistemas de cooperação que se pretendem estruturados no sentido "top down". Mais prováveis de alcançarem efetividade serão aqueles movimentos orientados no sentido "bottom up", que estão legitimados na experiência de convivência coletiva. A legitimidade dentro da rede, por sua vez, é a obtenção de status e legitimidade dentro desse ambiente (PODOLNY e PAGE, 1998). Por isso, ao participar de uma rede, uma organização busca legitimidade perante o ambiente institucional existente (DiMAGGIO e POWELL, 1983). Inclusive, por muitas vezes, as organizações têm comportamentos estruturalmente isomórficos para buscar essa legitimidade (DiMAGGIO e POWELL, 1983), ou seja, as organizações buscam homogeneidade e similaridade com os valores institucionalmente estabelecidos dentro da rede para obter legitimidade. Isso quer dizer que há uma série de capitais sociais que são permutados entre as organizações até que se forme um tecido dos valores e normas institucionalizados na rede, os quais as organizações buscam estar corroborantes.

A criação desse ambiente de rede propulsor de valores e normas sociais é, portanto, determinante para a forma pela qual se dão as relações das organizações. Isso implica dizer que essas relações, em especial, as de caráter econômico, estão embutidas na realidade social na qual elas acontecem (GRANOVETTER, 1985), de forma, portanto, que as institucionalizações econômicas são socialmente estabelecidas (BERGER e LUCKMANN, 1966). Daí surge a eminência do termo "embeddedness" (GRANOVETTER, 1985) aplicado às redes interorganizacionais (e.g. GULATI, 1998), ou numa tradução para o português, a "imersão social" (BALDI e VIEIRA, 2006). Isso quer dizer que toda a rede interorganizacional está inserida num contexto social, principalmente quando a rede está espacialmente concentrada num mesmo local. 
Esse processo de formação estrutural e institucional de redes interorganizacionais tem influência decisiva do desenvolvimento do capital social envolvido com a rede (WALKER, KOGUT e SHAN, 1997). Portanto, é imprescindível que exista uma gama de conhecimentos sociais para que as organizações as quais participam de redes aprendam. Sobre isso, é fundamental diferenciar a concepção de aprendizado em ambientes de rede. Deve-se ter em mente que, por mais que muitos participantes de redes interorganizacionais tenham como objetivo participar da rede para adquirir conhecimentos e know-hows técnicos, o aprendizado da participação das redes não se limita a isso. Até porque os ganhos com esses conhecimentos são de curto a médio prazo, dado que a curva de aprendizado em redes geralmente é decrescente ao longo de seu desenvolvimento (POWELL, KOPUT, SMITH-DOERR et al., 1999). Existe também uma série de conhecimentos sociais que estão envolvidos no ambiente criado pela rede que não devem ser menosprezados. Esse conhecimento social, uma vez institucionalizado dentre os indivíduos, faz parte da realidade de forma objetiva, de forma a poder ser transmitido diretamente, nas relações sociais (ZUCKER, 1977). Assim sendo, toda a ordenação, classificação e compreensão dos dados obtidos num ambiente são adquiridos pela visão de mundo do indivíduo (SCOTT, 2008), essa visão que está imersa no ambiente da rede.

Com base nisso, é importante entender que as redes interorganizacionais são, de fato, palco para que exista um ambiente comunizado capaz de oferecer aprendizado social aos seus participantes (KRAATZ, 1998), desde que haja uma colaboração que permita a geração de um ambiente de trocas (POWELL, KOPUT e SMITH-DOERR, 1996). Assim sendo, a formação de redes interorganizacionais induz a criação de um ambiente propício ao aprendizado institucional dos seus membros sobre como agir trabalhando na rede específica a que se pertence (CARNEIRO DA CUNHA e PASSADOR, 2006).

\section{O capital social nas redes interorganizacionais}

Considerando que o sucesso das organizações está ligado à forma pela qual ela lida com suas relações externas, principalmente no caso dos empreendimentos nascentes (VASSOLO e WEISZ, 2004), a faceta mais importante do ambiente organizacional são suas relações sociais externas (GULATI, 1998). Dessas relações emerge o capital social entre os participantes da rede, o que o torna um assunto de suma importância para se entender as relações de interações entre os agentes (PORTES, 1998). Diante disso, o capital social está relacionado aos recursos disponíveis em uma rede de relacionamentos entendida e reconhecida entre as organizações participantes (BOURDIEU, 1985). O capital social é um importante fator para criação do capital humano, o que faz com que ele seja oriundo de relações nas quais existem melhores condições de cooperação e coordenação entre os indivíduos (COLEMAN, 1988). Esse tipo de capital é característico de organizações sociais, cujas ações cooperadas e solidárias trazem benefícios mútuos (PUTNAM, 1993).

Para criação dessa cooperação entre organizações, é necessário haver confiança prévia entre elas (GULATI, 1995), sendo a confiança um elemento constituinte do capital social. Com o tempo, os participantes da rede passam a apoiar essa confiança em normas formalmente constituídas e se dispondo a viver pelas normas da comunidade e com a existência de sansões, para punir aqueles que desrespeitassem essas normas. O capital social representa normas, mesmo se não-institucionalizadas (BOURDIEU, 1985), que facilitam as ações coletivas para o benefício mútuo (WOOLCOCK, 1998).

A partir de então, podemos afirmar que existe uma consciência coletiva entre os participantes de uma rede, que faz o indivíduo agir em função do coletivo e não estritamente pelos interesses próprios (BIUTTENCOURT e ABRAMOVAY, 2003), havendo então comprometimento individual ao bem-estar da coletividade (LEANA e VAN BUREN III, 1999). Dessa forma, o capital social favorece o desenvolvimento por meio de construção de infraestrutura relacional, serviços e formas de integração entre as empresas (TRIGILIA, 2001). Somente com a difusão do capital social é possível potencializar elementos invisíveis, porém, totalmente operantes no contexto do desenvolvimento (KLIKSBERG, 1999). Nessa linha de pensamento, Melo Neto e Froes (2002) dizem que o capital social é uma forma superior de capital, capaz de 
gerar desenvolvimento sustentado nos laços de cooperação, solidariedade e confiança, que estão embutidos na base social e cultural da comunidade a qual a organização pertence.

A existência e a criação de um ambiente cultural semelhante também estão relacionadas à formação de capital social, que impulsiona a criação de um ambiente culturalmente comum entre os participantes da rede. Por isso que o capital social de uma comunidade deve ser medido de acordo com o histórico da rede e suas relações sociais (LIN, 1999), que molda a estrutura social de determinada comunidade. Isso se explica porque é necessário haver laços culturais provenientes da vivência local e do compartilhamento de experiências entre os indivíduos, antes que se institucionalizem sistemas de troca e união entre os envolvidos (FISCHER, 2004). Situações compartilhadas e vivenciadas pelos indivíduos criam uma cultura comum que influencia na geração do capital social (MELO NETO e FROES, 2002). Dessa forma, uma cultura semelhante serve de meio para os indivíduos se reconhecerem mutuamente, crescerem em conjunto e desenvolverem a autoestima coletiva (KLIKSBERG, 1999). No mais, a participação da cultura comum nesse processo também ganha relevância, quando se pondera que fatores como solidariedade, altruísmo, respeito e tolerância são disseminados por meio do capital social, sendo consideradas normas sociais que estão enraizadas na cultura comunitária (KLIKSBERG, 1999).

Diante do exposto, a existência dos elementos de capital social é de suma importância para a própria reprodução e sobrevivência de uma estrutura interorganizacional ao longo do tempo, sendo importante haver a manutenção e o reinvestimento de uma estrutura capaz de manter as relações sociais entre os membros da rede (WALKER, KOGUT e SHAN, 1997).

\section{A presença de agentes intermediadores}

Fica eminente que o sucesso de um arranjo interorganizacional local depende de iniciativas que vão além da busca de vantagens competitivas locais, que podem ter caráter individual. Devem existir ações colaborativas que estimulam a capacidade conjunta da rede em gerar valor. Mesmo havendo essa necessidade de capital social numa rede para sua manutenção bem-sucedida, por muitas vezes, são necessárias iniciativas que mantenham ativas as relações das organizações. Daí a importância de uma governança que possa sempre dar prosseguimento às atividades da rede. Provan e Kenis (2008) dizem que uma rede de organizações pode ser governada por três formas: (1) auto-organização, em que não existe a governança concentrada em um agente e as relações entre organizações ocorrem conforme a institucionalização social da rede; (2) presença de uma empresa-líder (chamada aqui de organização central) que coordena as ações entre as organizações participantes da rede e que socialmente detém poder e influência sobre os demais membros da rede; (3) presença de uma entidade administrativa autônoma que realiza a gestão de forma mais profissional. $O$ presente estudo foca no terceiro tipo de governança de rede. Isso implica que os intermediadores aqui abordados são aqueles que atuam independentemente nas funções de coordenação das ações da rede. Os intermediadores aqui podem ou não ter o papel de consultor técnico, o que inclusive pode ajudar positivamente no desenvolvimento de pequenas e médias empresas (BERRY, SWEETING e GOTO, 2006), como é, por exemplo, o caso de incubadoras de empresas. No entanto, o que delimita o tipo de governante abordado no presente estudo são suas ações de coordenação da rede.

Tem-se, portanto, agentes que realizam a governança das redes e que detêm o poder de decidir e, em alguns casos, legislar (mesmo que até certo ponto) as relações entre os participantes, no intuito de se manterem o controle formal e as leis estipuladas na rede. Por isso, a natureza da governança das redes interorganizacionais define os padrões de institucionalização da rede, de forma a controlar e alinhar as ações das organizações participantes (PARK, 1996). A governança de uma rede está relacionada à sua coordenação, que pode ser estipulada desde sistemas sociais orgânicos (informais) até estruturas burocráticas entre as organizações, com relações contratuais entre elas (JONES, HESTERLY e 
BORGATTI, 1997). Por isso os intermediadores acabam por ter papel de intermediadores de conflitos e de definir as normas válidas, mesmo que por coerção, dentro do ambiente institucional da rede.

No entanto, a real vantagem da participação desses agentes intermediadores ainda não é um consenso entre os estudiosos das redes interorganizacionais. Por um lado, Telles (2002) observou, por meio de uma pesquisa realizada em um APL da região de Ribeirão Preto (SP), que, para formação da rede, existe um receio nas empresas envolvidas quando há a participação de um intermediador. Os gestores se sentem desconfiados sobre as reais intenções dos intermediadores para fomentar uma associação de organizações. De outro lado, Hastenreiter Filho (2005) defende que essas organizações de suporte (intermediadores) são importantes para sensibilizar as empresas e despertá-las para as ações associativas e sustentar a própria rede. $\mathrm{O}$ autor defende ainda que as empresas que ingressam nesses programas de redes desenvolvidos por organizações de suporte já costumam ter uma configuração inicial estabelecida, o que dá uma real importância do papel das organizações de suporte no processo de formação de redes. Por fim, Hastenreiter Filho (2005) alega, por meio de estudos empíricos, que as organizações de suporte são importantes para: a difusão de conhecimentos técnicos; a construção das redes; o planejamento e a condução das atividades da rede; a resolução de conflitos (apesar de que indiretamente, já que ela constitui leis das redes, mas é tida como especialista para resolver conflitos).

No Brasil, sabe-se que sistemas locais têm como um de seus condicionantes de sucesso as políticas públicas (SUZIGAN, GARCIA e FURTADO, 2007). Essas que estimulam esses agentes desenvolvimentistas, dado que há interesse no desenvolvimento econômico regional obtido por meio de efeitos positivos do aumento da produção, da qualidade dos produtos, da incorporação de valores agregados, das exportações e do desenvolvimento do mercado interno (NORONHA e TURCHI, 2005). Como destaque no país, podem ser citados os trabalhos realizados por organizações terceiras, como o Sebrae (Serviço Brasileiro de Apoio às Pequenas e Médias Empresas) e a Fiesp (Federação das Indústrias do Estado de São Paulo), tal como por algumas secretarias municipais ligadas às prefeituras locais. Cabe a esses agentes assumirem uma estrutura de governança adequada à rede que irão governar, dentre eles, o contexto social-cultural e político local, tal como Suzigan, Garcia e Furtado (2007, p.426) afirmam:

Este talvez seja o condicionante mais importante da possibilidade e da forma de governança em APLs. É desse contexto multifacetado e geralmente específico a cada local que provém alguns dos mais importantes elementos básicos das formas de governança possíveis em APLs: a existência de solidariedade, a tendência à coesão social, a confiança conquistada por meio de frequentes [sic] interações, e a emergência de lideranças locais. Essas são características que, quando existem, estão fortemente arraigadas e fazem parte da história e do ideário local. Portanto, dificilmente podem ser transplantadas ou imaginadas como atributos genéricos de arranjos ou sistemas locais de produção.

\section{Procedimentos e escolhas metodológicas}

A primeira consideração a fazer é estabelecer se o foco de análise do estudo é sobre um ator específico "egocentric" - e sua atuação em rede ou em toda a rede - "whole-network" (MARSDEN, 2005). Sobre esse ponto, é importante deixar claro que o objetivo do estudo consistiu em entender a construção histórico-social de uma rede e a participação, em especial, da atuação de agentes intermediadores. Ou seja, o objeto de estudo era a rede e não o agente intermediador. Essa separação deve ser bem estipulada para que haja uma coleta de dados empíricos adequada aos objetivos estabelecidos.

Diante disso, utilizou-se a concepção temporal de Halinen e Törnroos (2005) para estudos de caso de redes interorganizacionais. Para os autores, o estudo de caso de redes interorganizacionais deve estar embasado no contexto ao qual a rede está inserida. Os autores alegam que essas análises individuais estão dentro de uma 
concepção temporal na qual o pesquisador deve entender o histórico da rede, os atuais mecanismos de funcionamento da rede e deve entender as expectativas futuras da rede. Ou seja, nessa concepção, a rede é fruto de um contexto histórico-social no qual as organizações estão inseridas e essas influências vão definir diretamente a atual situação da rede e as expectativas futuras dela.

Figura 1

Estrutura geral para análise de redes interorganizacionais

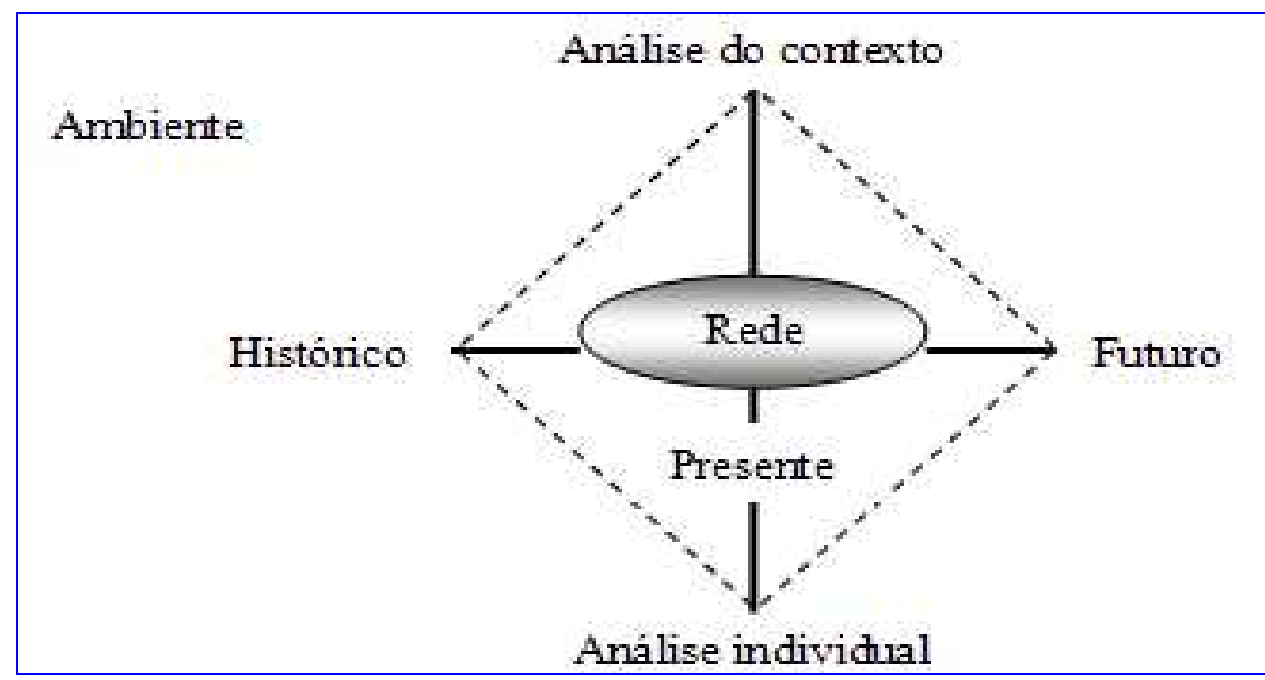

Fonte: Halinen e Törnroos, 2005, p.1290.

Apoiando-se nesse conceito de um estudo de caso que busque uma noção temporal da rede, buscou-se respaldo empírico na experiência do APL de calçados de Birigüi (localizado no interior do Estado de São Paulo). Essa escolha se justifica porque, no momento da abordagem aos respondentes da pesquisa, o APL de calçados de Birigüi era, formalmente, recém-inaugurado por uma iniciativa de associação coordenada pelo Sindicato das Indústrias do Calçado e Vestuário de Birigüi (Sinbi). Dessa forma, a escolha desse objeto de pesquisa proporcionou realizar uma abordagem de campo no momento em que o APL se constituía formalmente, o que atendia aos objetivos propostos pela pesquisa.

\section{Protocolo de pesquisa}

O protocolo de pesquisa foi elaborado, portanto, com o intuito de abranger a perspectiva temporal da rede, com foco no seu processo de formação. Para tal, elaborou-se um instrumento de pesquisa (roteiro de entrevista semiestruturada) que foi utilizada para a abordagem com gestores de pequenas e médias empresas de Birigüi. Procurou-se incluir perguntas na entrevista capazes de compreender as interpretações dos gestores das pequenas e médias empresas, perante a troca de capital social com os demais membros da rede e com a evolução das relações com os demais participantes do APL. Procurou-se também estabelecer perguntas que pudessem esclarecer a percepção em relação ao papel do agente intermediador na visão desses gestores. A Figura a seguir sintetiza os pontos chaves a serem abrangidos nas perguntas utilizadas no questionário semiestruturado usado para a pesquisa de campo. 
Figura 2

Síntese do protocolo de pesquisa

\begin{tabular}{|c|c|c|}
\hline $\begin{array}{c}\text { Passado } \\
\text { Geração do ambiente } \\
\text { institucional }\end{array}$ & $\begin{array}{c}\text { Presente } \\
\text { Estabelecimento formal do AP } \\
\text { e início das atividades }\end{array}$ & $\begin{array}{c}\text { Futuro } \\
\text { Expectativas de ganhos com } \\
\text { a participação no APL }\end{array}$ \\
\hline $\begin{array}{l}\text { - } \quad \begin{array}{l}\text { Existência prévia de } \\
\text { relacionamentos informais }\end{array} \\
\text { - } \quad \text { Histórico de relações e } \\
\text { associações entre os } \\
\text { membros do APL }\end{array}$ & 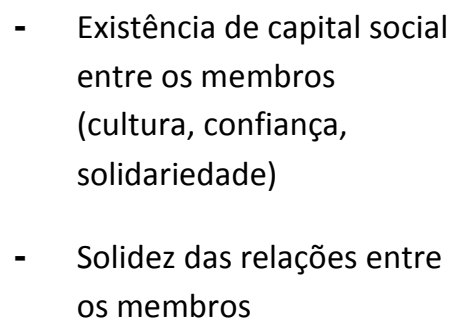 & 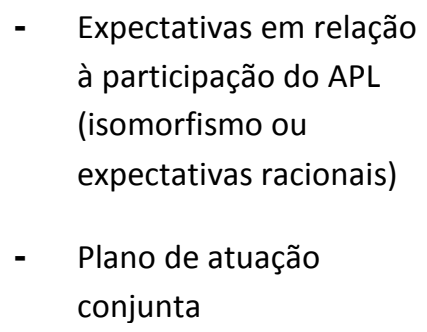 \\
\hline
\end{tabular}

Fonte: Elaborado pelos autores.

Para análise da perspectiva do passado, foi realizada uma revisão de literatura sobre os estudos e documentos que abordavam o histórico do desenvolvimento econômico e social do município de Birigüi, em especial, da indústria de calçados da região. Esse levantamento foi complementado pelo relato de experiências vividas por gestores da região. Com isso, buscou-se identificar traços culturais, sociais e econômicos que pudessem auxiliar na sustentação da percepção histórica da cidade. Para a perspectiva presente e futura, utilizou-se a abordagem de campo, na qual se preferiu a entrevista pessoal, uma escolha que foi sustentada por dois motivos: (1) Em decorrência de uma tentativa frustrada de uma abordagem por e-mail via questionário (apenas um respondente), confirmando os estudos de Baruch (1999) que afirma que questionários enviados aos gestores têm um baixo índice de respostas; (2) Porque o retorno sobre esse único respondente trouxe dificuldades para aprofundar a compreensão do fenômeno por parte do pesquisador de campo, o que se justifica porque: (a) não se teve o contato presencial para se criar uma sistemática de entrevista semiestruturada, necessária para entender alguns elementos da formação social dos participantes (não há um roteiro totalmente definido quando se tem uma abordagem totalmente exploratória); (b) não haveria a imersão do pesquisador no ambiente social de Birigüi, que poderia oferecer dicas sobre a percepção do APL; (c) alguns elementos de caráter implícito em relação às sensações do entrevistado sobre a sua formação social não seriam possíveis de serem compreendidas sem que houvesse uma socialização (mesmo que mínima) com o entrevistado. Por fim, as entrevistas realizadas pessoalmente tiveram em média, a duração aproximada de 25 minutos. Importante ainda ressaltar que, em alguns casos, houve complementarmente também visita in loco nos processos operacionais das organizações participantes.

A amostra abordada no presente estudo foi construída a partir da listagem das empresas que se propuseram a participar do programa de formação do APL de Birigüi capitaneado pelo Sinbi, que representavam uma população de 34 organizações, na qual a grande maioria se localiza no próprio município de Birigüi (SP) e eram produtoras de calçados ou de materiais correlatos. Dessas 34 empresas, 11 foram entrevistadas numa amostra por conveniência. Essa quantidade representa quase um terço (32,3\% do total) de empresas participantes do APL de Biriguii. No mais, foi realizada também uma entrevista com a gestora do Sinbi para identificar intenções do agente intermediador. 


\section{Resultados}

\section{A formação histórica do Arranjo Produtivo Local de Birigüi}

Conforme exposto na seção de procedimentos metodológicos, é fundamental que se entenda o contexto histórico no qual o APL de calçados de Birigüi foi formado. Portanto, em suma, as primeiras iniciativas importantes para o desenvolvimento desse polo calçadista surgiram na década de 1950, na qual a economia do município de Birigüi marcou-se pela transição da economia agrícola pela instalação das primeiras empresas produtivas de calçados na região (MUSEU BIRIGÜI, 2007). A quantidade de empresas no setor de calçados foi aumentando nas décadas subsequentes fazendo com que a cidade se caracterizasse pela sua especialidade na produção de calçados infantis (VEDOVOTTO, 1996; RIZZO, 2004), em detrimento dos arranjos já existentes de calçados masculinos em Jaú (SP) e calçados femininos no Rio Grande do Sul (VEDOVOTTO, 1996).

O surgimento dessas novas empresas foi respaldado pela grande dinâmica de criação de novos empreendimentos que pode ser dividida em dois momentos: num primeiro, que se caracterizou por empreendimentos criados por operários que aprenderam seu ofício nas antigas selarias existentes na cidade (VEDOVOTTO, 1996); num segundo momento, em que a criação de novas empresas empreendedoras se deu em decorrência do know-how existente de ex-funcionários de grandes empresas da região que buscaram seus próprios negócios (RIZZO, 2004). Ou seja, a indústria local de calçados tem um histórico de criação de novos empreendimentos sustentados pelo know-how gerado na própria localidade.

O arranjo foi-se desenvolvendo, nos anos 60 surgem mais 8 fábricas, nos anos 70 abrem mais 15 fábricas e nos anos 80 ocorre um boom no APL com o surgimento de 106 unidades fabris. Cumpre destacar que muitos microempresários aprenderam a fazer sapatos trabalhando como empregados, montaram negócios informais para depois legalizar as firmas e tiveram uma fase de ouro no início dos anos 80 (GRAÇA, 2007, p.118).

Atualmente, as empresas de Birigüi representam o maior polo de empresas produtoras de calçados infantis, com uma produção de 263 mil pares por dia e que emprega 19 mil pessoas (SINBI, s/d). A indústria calçadista de Birigüi conta ainda em 164 fábricas (PREFEITURA MUNICIPAL DE BIRIGÜI, 2010).

Nesse ambiente especializado na produção de calçados infantis, o sindicato foi uma figura presente na evolução da indústria de Birigüi. Para Amato Neto (2009), o sindicato de Birigüi, juntamente com o Serviço Nacional de Aprendizagem Industrial (SENAI), tem como principal função de promoção do APL por meio de cursos de qualificação de mão de obra para os diversos estágios de produção. No entanto, para entender seu papel na formação institucional da região, deve-se levar em conta que o sindicato (que é oriundo da própria cidade de Birigüi) detém valores que são institucionalizados nesse ambiente, já que ele existe desde 1979, mesmo tendo sofrido mudanças de nome e estrutura. Ele também estipula algumas normas de conduta do APL no sentido top-down, principalmente no que se refere à negociação sindical. Identificou-se ainda que ele é aberto às opiniões e sugestões dos seus membros sob uma gestão participativa, mas a decisão final ainda sim, está centralizada nesse agente intermediador. Segundo entrevista com uma das gestoras do sindicato, "a intenção do sindicato é de fomentar essa união das empresas da região", percebeu-se que a grande atividade realizada pelo sindicato era a identificação de necessidades dos participantes para mediar ações sobre essas demandas.

Sobre isso, Graça (2007, p.119) afirma que "[...] a partir dos anos 1980 o APL de Birigüi (SP) começa a desenvolver a sua vocação regional. As dimensões: econômica, espacial, tecnológica, social, ambiental e institucional começam a se formar. O Pólo [sic] atrai para o local as empresas correlatas e de apoio" (GRAÇA, 2007, p.119, grifo nosso). 
Portanto, relata-se que existiu a formação dos valores institucionalizados na região de Birigüi, o que inclui especialmente os participantes do APL. Sobre isso, Cícero (2007, p.38) corrobora as ideias de Graça (2007) sobre o sistema local dizendo que:

A sua característica mais marcante é o seu sistema de valores e de pensamento relativamente homogêneo - expressão de uma certa ética do trabalho e da atividade, da família, da reciprocidade e da mudança - o qual, de alguma maneira, condiciona os principais aspectos da vida. [...] Paralelo a isso, desenvolve-se um conjunto de instituições (o mercado, as empresas, a família, a igreja, a escola, mas também as autoridades e as organizações políticas e sindicais locais) e regras para que esses valores perdurem no tempo (CÍCERO, 2007, p.38).

As afirmativas apresentadas comprovam que existem normas sociais institucionalizadas em Birigüi que servem de base para o relacionamento entre as empresas operacionais e de apoio do APL. No mais, afirma-se que há um nível de reciprocidade entre os participantes da rede. Por mais que não se possa afirmar que existe uma estrutura consolidada de capital social com laços fortes, percebe-se haver um histórico de relações informais entre os membros da indústria da região.

\section{A institucionalização de valores em Birigüi: histórico e construção de valores}

Se por um lado Birigüi conta com sindicatos patronais que denotam a existência de fortes instituições (AMATO NETO, 2009), por outro, existem também institucionalizações construídas no APL cujos agentes intermediadores têm considerável participação ativa no histórico de relações juntamente com as organizações envolvidas, mesmo que de forma modesta. Apesar de a formalização do APL ser uma iniciativa que vinha ocorrendo há três meses antes na pesquisa realizada, já existia um histórico das relações cooperadas entre as organizações da indústria calçadista e de vestuário da região de Birigüi. A grande maioria das empresas entrevistadas disse estar fazendo parte desse movimento formal para criação do APL através do Sinbi há relativamente pouco tempo. As respostas demonstraram que a maioria das empresas que participavam dessa criação do APL estava envolvida nessa preparação há cerca de um ano. Entretanto, é importante ressaltar aqui que muitos entrevistados alegaram que têm realizado ações conjuntas com outras empresas do setor há mais tempo, havendo inclusive cooperações que que já estão sendo realizadas há aproximadamente 10 anos.

Numa das entrevistas pôde-se perceber ainda a existência de grupos de cooperação formais prévios ao APL. O destaque foi o consórcio de exportação, no qual empresas aliaram-se formalmente no intuito de participar de feiras internacionais e de incrementar suas exportações. Houve, inclusive, a criação de uma marca própria, cujo objetivo foi aumentar a participação desses participantes no mercado internacional. Um dos entrevistados dessa pesquisa que participou desse grupo alegou que "com a queda do preço do dólar passou a não compensar mais manter o grupo", já que com a queda da taxa cambial os ganhos provenientes das exportações passaram a ser menores.

Sob a perspectiva informal, os entrevistados alegaram serem amigos ou colegas de alguns outros empresários do ramo, entretanto, alegaram haver relações apenas ocasionais entre eles. A justificativa dada pelos entrevistados, para haver essa relação informal, foi a proximidade que a região proporciona às pessoas, fazendo com que elas acabem se conhecendo, ainda que não profundamente.

Apesar de se perceber um histórico de iniciativas pequenas de cooperação entre empresas, não se pode dizer que existe um alto grau de capital social, principalmente porque se percebeu que a cultura de associativismo é algo que, segundo os entrevistados, ainda estava começando a ser desenvolvida. 


\section{A união formal do APL de Birigüi: contexto presente}

Até o momento da realização do estudo empírico, as atividades do APL estavam num estágio inicial em que as empresas participantes estavam sob diagnóstico para o levantamento de suas necessidades mais imediatas e de possíveis incrementos sob a égide do APL. Portanto, o presente estudo não identificou haver necessidade social conjunta proveniente de vontades próprias dos participantes do APL que impulsionasse a união das empresas. O que houve foi uma iniciativa de um terceiro (agente intermediador) para incrementar os ganhos comerciais delas. Em termos de trocas de capital social, o que se observou foi que os entrevistados alegaram haver cultura semelhante, confiança entre os participantes e solidariedade conjunta, no entanto, eles deixaram claro que são elementos de segundo plano, que advêm depois das relações econômicas. Portanto, os laços entre as organizações, munidos de capital social, não se demonstraram em sua plena maturidade no momento da abordagem do estudo de campo.

Além de as vantagens identificadas pelos participantes serem majoritariamente econômicas, não se observou, tampouco, a percepção de como induzir esse desenvolvimento econômico de forma conjunta. Os elementos de capital social, tidos como implícitos e como objetivos não-primários, são colocados como consequentes aos ganhos financeiros e não como um elemento preterível para se atingir um nível maior de competitividade (que leva ao ganho econômico). Assim, não se identificaram iniciativas para fortalecer os relacionamentos sociais entre os participantes. Disso, perceberam-se dois elementos relevantes: (1) Existiu de fato um histórico tanto de relações comerciais anteriores quanto de relações sociais informais entre os membros da rede, mas não houve um laço forte o suficiente para que os valores econômicos e comerciais superassem a relação social entre eles; (2) Por si só, as empresas de Birigüi não foram capazes de articularem-se de forma sustentável e, tampouco, de formar capital social suficiente para que essas iniciativas fossem oriundas de iniciativas próprias.

Sobre os motivos que levaram os gestores dessas empresas a se associarem formalmente, percebeu-se que os entrevistados, na maioria das vezes, não sabiam dizer com clareza quais os ganhos que eles poderiam ter com a participação da rede. Havia uma perspectiva de que aquele grupo poderia trazer vantagens futuras para eles. A explicação para isso é que existe um sentimento por parte desses gestores de pertencer ao grupo organizado do APL de Birigüi, comportamento esse que, por vezes, sobrepõe-se às questões racionais de participação da rede. Há, portanto, um isomorfismo de comportamento que leva os empresários a participarem do grupo.

\section{As expectativas dos participantes do APL de Birigüi}

As vantagens dos ganhos provenientes das ações cooperadas de um aglomerado organizacional são vistas pelos empresários entrevistados de Birigüi apenas como algo explícito, ligado à redução de custos, riscos e participação de mercado. O que se observou entre todos os entrevistados é que no momento das entrevistas existiam poucos ganhos concretos adquiridos por meio da participação do APL. Os entrevistados alegaram que isso aconteceu porque o processo de formalização e união dos empresários ainda estava no início. Por isso, o que se percebeu é que as vantagens do APL concentravam-se não nos poucos ganhos concretos obtidos com o processo de formação do APL, mas nas expectativas de ganhos futuros provenientes do desenvolvimento e crescimento do APL.

Sobre essas vantagens, as iniciativas planejadas para realização pelo Sindicato estavam sendo concentradas em treinamentos e palestras, enquanto as ações esperadas pelos participantes do Sindicato focavam-se mais nas relações sindicais que nas ações de colaboração conjunta. Aliada a isso, a expectativa identificada na maioria dos entrevistados é que o plano de expansão econômica do APL possa favorecê-los num futuro 
próximo. No momento da abordagem empírica, eles acreditavam que os grandes ganhos em participar do APL ainda estavam por vir.

\section{Discussões finais}

A principal conclusão a que se chega diante dos resultados obtidos é que no caso de Birigüi, a presença de um agente intermediador, por si só, não garantiu a formação de laços de proximidade entre os membros da rede interorganizacional, e tampouco garantiu a troca de capitais sociais entre eles. O sindicato (agente intermediador) tinha um papel relevante como agente externo, imparcial, que organiza e promove iniciativas em prol do desenvolvimento econômico e comercial do APL. Sob a perspectiva econômica, percebe-se que o agente intermediador tem papel importante para unir interesses de curto prazo entre os membros da rede, no intuito de gerar consórcios entre eles que trazem ganhos econômicos, que não seriam possíveis de forma isolada. No entanto, não houve evidências relevantes que pudessem colocar esse agente como indutor do desenvolvimento social do APL.

Portanto, do ponto de vista social, extrapolando a experiência de Birigüi para outras redes interorganizacionais, acredita-se que em redes nas quais não existam fortes laços munidos de capital social, $o$ agente intermediador acaba assumindo uma figura de fomentador, sem o poder para alavancar relações socialmente fortes na união das organizações. Isso se justifica por dois grandes motivos: (1) O processo institucional que não detém maturidade suficiente para legitimar o agente intermediador como governante das complexidades sociais e econômicas da rede; (2) As relações são focadas no aspecto comercial e econômico, mas não prioritariamente social, o que faz com que as ações do intermediador estejam sustentadas por uma racionalidade de mercado e não uma lógica social. Por isso, sem o desenvolvimento institucional da rede, as iniciativas realizadas pelo intermediador da rede acabam tendo função assessória no funcionamento econômico e, principalmente, social da rede.

Adicionalmente, acredita-se que os agentes intermediadores nesse caso deveriam ter um papel de catalisadores para a proximidade e o intermédio das relações entre membros de uma rede interorganizacional, ao mesmo passo em que eles não deveriam assumir um papel maior do que realmente representam para a rede. Eles são, sim, importantes, mas não são elementos fundamentais para a formação de redes. Assim sendo, o agente é um estimulante, mas não o elemento central da rede. O elemento central são as relações em si e o output que a rede pode produzir.

Essa conclusão é extremamente relevante para as diversas iniciativas existentes no Brasil para a formação de redes, porque não basta ao poder público simplesmente unir as organizações numa formalização de relação contratual para a efetividade completa das trocas entre organizações. Deve haver previamente à presença de um intermediador formalizador um histórico de semelhança e colaboração entre os membros da rede para que a formalização possa refletir a existência de um contrato social previamente instituído, e não um contrato social imposto pelo intermediador. Por isso, nos casos em que não existe esse ambiente de trocas de capital social instalado, o que essas iniciativas de intermédio de organizações podem fazer é, no máximo, criar ambientes de convivência e socialização das organizações participantes. Por mais que o agente intermediário possa estimular os relacionamentos entre os participantes, ele não pode oferecer o capital social para eles, que só existe após consecutivas trocas relacionais. Deve estar claro que o que traz a troca de capitais sociais entre os membros da rede não é a presença de agentes intermediadores, mas sim a experiência conjunta, o legado e a convivência acumulada entre eles que geram os próprios laços fortes ou laços tipo "cola". O ideal é que um agente intermediador se adapte ao contexto social-cultural e político local já existente e assim promova ações que unam a colaboração efetiva entre os participantes. Dessa forma, o agente intermediário apenas estimula uma relação social com capital social já construído, sem ser o responsável central por essa construção, que demanda tempo e experiências acumuladas. Isso maximizaria as ações do agente intermediador. 
No entanto, ressalta-se que isso não significa que, como a sistemática social natural entre os membros da rede é a responsável por construir os laços de proximidade entre eles, os agentes intermediadores tenham um papel renegado em ambientes de redes interorganizacionais. Ou seja, não se defende aqui que não deva existir iniciativas de agentes intermediadores em redes interorganizacionais. O que se acredita é que os agentes intermediadores não devem ser considerados como soluções plug-and-play para a formação de redes, não devendo, portanto, extrapolar suas reais capacidades de agente articulador com atuação efetiva. Deve-se ter em mente que iniciativas e políticas públicas focadas em atuar exclusivamente por meio de agentes intermediadores são apenas uma parte de uma série de ações voltadas à formação de redes. É importante estimular a proximidade e as relações entre os participantes da rede para se ter uma formação de APL bem-sucedida. Agentes intermediadores, por si só, são iniciativas insuficientes se não existem laços fortes e instituições sociais formadas orientadas à atuação coletiva.

Observando também a questão da participação da organização na rede dentro da perspectiva temporal futura, tem-se um contexto em que o isomorfismo atua sobre alguns participantes. Ou seja, o participante age isomorficamente para participar da rede, quando se percebe que ele não detém com clareza os ganhos provenientes ao associativismo e, tão pouco, tem uma estratégia claramente definida sobre as atividades em conjunto que ele poderia realizar. Percebeu-se que por mais que não exista uma coerção legal ou contratual para novos participantes aderirem formalmente à rede, existe um sentimento entre os participantes entrevistados de que essa associação pode trazer vantagens, mesmo não sendo no curto prazo e que, por vezes, o entrevistado não tivesse claro quais seriam elas. Isso implica que o agente intermediador pode incentivar a rede a ter mais participantes quando ele consegue aguçar nesse participante a vontade de participação, mesmo que sem um respaldo totalmente racional para a formação de alianças.

\section{Limitações e recomendações para estudos futuros}

O presente estudo tem algumas limitações no que tange às escolhas metodológicas da pesquisa empírica. A primeira limitação do método do estudo de caso consiste que, por mais que a experiência da formação do APL de Birigüi seja um caso relevante e importante para a construção de teorias a respeito da realidade (EISENHARDT e GRAEBNER, 2007), as conclusões não necessariamente podem ser generalizadas. Isso porque cada caso especificamente é amarrado a uma situação específica (MacNEALY, 1997). Por isso, recomenda-se que a pesquisa se estenda para outros APLs de calçados no Brasil para que se possa viabilizar uma comparação mais homogênea possível entre casos. Diante disso, a recomendação é que se estude a presença de agentes intermediadores em outros APLs de calçados, como, por exemplo, nos casos de Franca (SP), Jaú (SP), Nova Serrana (MG), Belo Horizonte (MG), Cariri (CE), São João Batista (SC), Vale do Rio Sinos (RS) e Farroupilha (RS).

No mais, a formação de redes interorganizacionais pode ser interpretada sob diversas óticas teóricas, epistemológicas e conceituais. Sugere-se realizar esse mesmo tipo de estudo por meio da Teoria Econômica, embasando-se nos conceitos do Modelo de Utilidade Descontada Constante (ou mais conhecido como Modelo de Escolhas Intertemporais) desenvolvido por Samuelson (1937) e posteriormente complementada por construtos psicológicos emocionais, tal como Giannetti (2005) aponta existir. Trata-se de uma teoria em que o indivíduo decide qual o melhor momento para alocar seus custos e benefícios ao longo do tempo, dentro de uma perspectiva racional, mas que se apercebeu de que também pode sofrer influência de suas emoções. A ideia é verificar se os resultados aqui encontrados são válidos perante outra corrente de pensamento, que também verifica o comportamento dos indivíduos numa perspectiva temporal. Por fim, recomenda-se ainda que os estudos posteriores sobre a presença de agentes intermediadores na evolução e formação das redes interorganizacionais estruturem-se empiricamente de forma longitudinal. 


\section{Referências}

AMATO NETO, J. Gestão de sistemas locais de produção e inovação. (Clusters / APLs). São Paulo: Atlas, 2009.

BALDI, M.; VIEIRA, M. M. F. Calçado do Vale: imersão social e redes interorganizacionais. RAE - Revista de Administração de Empresas, v.46, n.3, p.16-27, 2006.

BARRINGER, B. R.; HARRISON, J. S. Walking a tightrope: creating value through interorganizational relationships. Journal of Management, v.26, n.3, p.367-403, 2000.

BARUCH, Y. Response rate in academic studies - a comparative analysis. Human Relations, v.52, n.4, p.421-438, 1999.

BERGER, P.; LUCKMANN, T. The social construction of reality: a treatise in the sociology of knowledge. Garden City: Anchor Books, 1966.

BERRY, A. J.; SWEETING, R.; GOTO, J. The effect of business advisers on the performance of SMEs. Journal of Small Business and Enterprise Development, v.13, n.1, p.33-47, 2006.

BITTENCOURT, G. A.; ABRAMOVAY, R. Inovações institucionais no financiamento à agricultura: o Sistema Cresol. Revista Economia Ensaios, v.16, n.1, p.179-207, 2003.

BORGATTI, S. P.; FOSTER, P. C. The network paradigm in organizational research: a review and typology. Journal of Management, v.29, n.6, p.991-1013, 2003.

BOURDIEU, P. The social space and the genesis of groups. Theory and Society, v.14, n.6, p.723-744, 1985.

BUTLER, J. E.; HANSEN, G. S. Network evolution, entrepreneurial success, and regional development. Entrepreneurship \& Regional Development, v.3, n.1, p.1-16, 1991.

CAPRA, F. O ponto de mutação: a ciência, a sociedade e a cultura emergente. São Paulo: Cultrix, 1982.

CARNEIRO DA CUNHA, J. A.; PASSADOR, J. L. Alianças estratégias de organizações: o aprendizado institucional na formação de redes. In: $30^{\circ}$ ENCONTRO DA ASSOCIAÇÃO NACIONAL DE PÓS-GRADUAÇÃO E PESQUISA EM ADMINISTRAÇÃO, 30., 2006, Salvador. Anais... Belo Horizonte: ANPAD, 2006.

CÍCERO, E. C. Uma análise da indústria de calçados de Birigui no contexto de flexibilização produtiva. Universidade Estadual Paulista, Presidente Prudente, SP, 2007.

COLEMAN, J. S. Social capital in the creation of human capital. The American Journal of Sociology, v.94, Supplement, p.S95-S120, 1988.

DAS, T. K.; TENG, B. Alliance constellations: a social exchange perspective. Academy of Management Review, v.27, n.3, p.445-456, 2002.

DiMAGGIO, P. J.; POWELL, W. W. The iron cage revisited: institutional isomorphism and collective rationality in organizational fields. American Sociological Review, v.48, n.2, p.147-160, 1983.

DOZ, Y. L. The evolution of cooperation in strategic alliances: initial conditions or learning processes? Strategic Management Journal, v.17, Special Issue, p.55-83, 1996.

EBERS, M. Explaining inter-organizational network formation. In: EBERS, M. (Org.). The formation of interorganizational networks. New York: Oxford University Press, 1999.

EISENHARDT, K. M.; GRAEBNER, M. E. Theory building from cases: opportunities and challenges. Academy of Management Journal, v.50, n.1, p.25-32, 2007. 
FISCHER, T. M. D. La experiencia de desarrollo local em ciudad patrimonio: el caso de Salvador de Bahia. IX COGRESSO DEL CLAD, 9., 2004, Madri, Espanha. Anais... Caracas: CLAD, 2004.

GAJDA, R. Utilizing collaboration theory to evaluate strategic alliances. American Journal of Evaluation, v.25, n.1, p.65-77, 2004.

GIANNETTI, E. O valor do amanhã: ensaio sobre a natureza dos juros. São Paulo: Companhia das Letras, 2005.

GIDDENS, A. The constitution of society: outline the theory of structuralism. Los Angeles: University of California Press, 1984.

GIOIA, D. A.; PITRE, E. Multiparadigm perspectives on theory building. Academy of Management Review, v.15, n.4, p.584-602, 1990.

GÖDEL, K. A remark about the relationship between relativity theory and idealistic philosophy. In: SCHILPP, P. A. (Org.). Albert Einstein: philosopher-scientist. Cambidge: Cambridge University Press, 1949.

GRAÇA, C. A. Governança e inovação tecnológica em APLs: um estudo de caso no APL calçadista de Birigüi (SP) (anos 1990 - 2000). Tese (Doutorado em Engenharia de Produção). Escola Politécnica - Universidade de São Paulo, São Paulo, 2007.

GRANDORI, A.; SODA, G. Inter-firm networks: antecedents, mechanisms and forms. Organization Studies, v.16, n.2, p.183-214, 1995.

GRANOVETTER, M. The strenght of weak ties. American Journal of Sociology, v.78, n.6, p.1360-1380, 1973.

. Economic action and social structure: the problem of embeddedness. American Journal of Sociology, v.91, n.3, p.481-510, 1985.

GULATI, R. Social structure and alliance formation patterns: a longitudinal analysis. Administrative Science Quarterly, v.40, n.4, p.619-652, 1995.

Alliances and networks. Strategic Management Journal, v.19, n.4, p.293-317, 1998.

; GARGIULO, M. Where do interorganizational networks come from? American Journal of Sociology, v.104, n.5, p.1439-1493, 1999.

HALINEN, A.; TÖRNROOS, J. Using case methods in the study of contemporary business networks. Journal of Business Research, v.58, n.9, p.1285-1297, 2005.

HASTENREITER FILHO, H. N. Acertos e desacertos dos principais programas de redes de cooperação interempresariais brasileiros. In: TEIXEIRA, F. (Org). Gestão de redes de cooperação interempresariais: em busca de novos espaços para o aprendizado e a inovação. Salvador: Casa da Qualidade, 2005.

HEDAA, L.; TÖRNROOS, J. Understanding event-based business networks. Time \& Society, v.17, n.2/3, p.319-348, 2008.

HOANG, H.; ANTONCIC, B. Network-based research in entrepreneurship: a critical review. Journal of Business Venturing, v.18, n.2, p.165-187, 2003.

JONES, C.; HESTERLY, W. S.; BORGATTI, S. P. A General theory of network governance: exchange conditions and social mechanisms. Academy of Management Review, v.22, n.4, p.911-945, 1997.

KLIKSBERG, B. Capital social y cultura, claves essenciales del desarollo. Revista de la Cepal, v.69, p.85-102, 1999. 
KNOBEN, J.; OERLEMANS, L. A. G.; RUTTEN, R. P. J. H. Radical changes in inter-organizational network structures: the longitudinal map. Technological Forecasting and Social Change, v.73, n.4, p.390-404, 2006.

KRAATZ, M. S. Learning by association: inter-organizational networks and adaptation to environmental change. Academy of Management Journal, v.41, n.6, p.621-643, 1998.

LEANA, C. R.; VAN BUREN III, H. J. Organizational social capital and employment practices. Academy of Management Review, v.24, n.30, p.538-555, 1999.

LEVINTHAL, D. A.; FICHMAN, M. Dynamics of inter-organizational attachments: auditor-client relationships. Administrative Science Quarterly, v.33, n.3, p.345-369, 1988.

LIN, N. Building a network theory of social capital. Connections, v.22, n.1, p.28-51, 1999.

LOWRIE, A.; McKNIGHT, P. J. Academic research networks: a key to enhancing scholarly standing. European Management Journal, v.22, n.4, p.345-360, 2004.

MacNEALY, M. S. Toward better case study research. IEEE Transactions on Professional Communication, v.40, n.3, p.182-196, 1997.

MARSDEN, P. V. Recent developments in network measurement. In: CARRINGTON, P. J.; SCOTT, J.; WASSERMAN, S. (Orgs.). Models and methods in social network analysis. New York: Cambridge University Press, 2005.

MARSHALL, A. Principles of economics. $8^{\text {a }}$ Ed. London: MacMillan, 1920.

MELO NETO, F. P.; FROES, C. Empreendedorismo social: a transição para a sociedade sustentável. Rio de Janeiro: Qualitymark, 2002.

MEYER, J. W.; ROWAN, B. Institutionalized organizations: formal structure as myth and ceremony. American Journal of Sociology, v.83, n.2, p.340-363, 1977.

MUSEU BIRIGÜI. Linha do Tempo. 2007. Disponível em: <http://www.museubirigui.com.br> Acesso em: 1 Abr. 2010.

NAHAPIET, J.; GHOSHAL, S. Social capital, intellectual capital and the organizational advantage. Academy of Management Review, v.23, n.2, p.242-266, 1998.

NORONHA, E. G.; TURCHI, L. Política industrial e ambiente institucional na análise de arranjos produtivos locais. Texto para discussão n.1076. Brasília: IPEA, 2005.

PARK, S. H. Managing an interorganizational network: a framework of the institutional mechanism for network control. Organization Studies, v.17, n.5, p.795-824, 1996.

PASSADOR, J. L.; CARNEIRO DA CUNHA, J. A. A formação de alianças e redes interorganizacionais. In: PASSADOR, C. S.; PASSADOR, J. L. (Orgs.). Gestão pública e desenvolvimento no século XXI: casos da Companhia de Desenvolvimento dos Vales São Francisco e do Parnaíba (Codevasf). São Paulo: Annablume, 2008.

PODOLNY, J. M.; PAGE, K. L. Network forms of organization. Annual Review of Sociology, v.24, p.57-76, 1998.

PORTES, A. Social capital: its origins and applications in modern sociology. Annual Review of Sociology, v.24, p.124, 1998.

POWELL, W. W.; KOPUT, K. W.; SMITH-DOERR, L. Interorganizational collaboration and the locus of innovation: networks of learning in biotechnology. Administrative Science Quarterly, v.41, n.1, p.116-145, 1996. 
; KOPUT, K. W.; SMITH-DOERR, L. et al. Network position and firm performance: organizational returns to collaboration in the biotechnology industry. In: ANDREWS, S.; KNOKE, D. (Orgs.). Research in the sociology of organizations. Greenwich: JAI Press, 1999.

PREFEITURA MUNICIPAL DE BIRIGÜI. Cidade - Estatística. 2010. Disponível em: http://www.birigui.sp.gov.br/site/ . Acesso em: 29 Nov. 2010.

PROVAN, K. G.; KENIS, P. Modes of network governance: structure, management, and effectiveness. Journal of Public Administration Research and Theory, v.18, n.2, p.229-257, 2008.

PUTNAM, R. The prosperous community: social capital and public life. American Prospect, v.13, p.35-42, 1993.

RING, P. S. The three T's of alliance creation: task, team and time. European Management Journal, v.18, n.2, p.152$163,2000$.

RIZZO, M. R. A indústria de calçados infantis de Birigüi. Dissertação (Mestrado em Economia Social e do Trabalho). Universidade Estadual de Campinas, Campinas, SP, 2004.

ROWLEY, T. J. Moving beyond dyadic ties: a network theory of stakeholder influences. Academy of Management Review, v.22, n.4, p.887-910, 1997.

SAMUELSON, P. A Note on measurement of utility. Review of Economic Studies, v.4, n.2, p.155-161, 1937.

SCOTT, W. R. Introduction: institutional theory and organizations. In: SCOTT, W. R.; CHRISTENSEN, S. M. (Orgs.). The institutional construction of organizations: international and longitudinal studies. Thousand Oaks: Sage, 1995.

Institutions and organizations: ideas and interests. $3^{\mathrm{a}}$ Ed. Thousand Oaks: Sage, 2008.

SIMMEL, G. Conflict and the web of group affiliations. New York: Free Press, 1955.

SINBI. Histórico e ações institucionais. s/d. Disponível em: <http://www.sinbi.com.br> Acessado em: 5 Abr. 2010.

SMITH-DOERR, L.; POWELL, W. W. Networks and economic life. In: SMELSER, N. J.; SWEDBERG, R. (Orgs.). The Handbook of Economic Sociology. $2^{\text {a }}$ Ed. Princeton: Princeton University Press, 2004.

SUZIGAN, W.; FURTADO, J., GARCIA, R. et al. Sistemas locais de produção: mapeamento, tipologia e sugestões de políticas. XXXI ENCONTRO NACIONAL DE ECONOMIA, 31., 2003, Porto Seguro. Anais... Rio de Janeiro: ANPEC, 2003.

; FURTADO, J.; GARCIA, R. Estruturas de governança em arranjos ou sistemas locais de produção. Gestão \& Produção,v. 14, n.2, p.425-439, 2007.

TELlES, L. O. (2002). Clusters e a indústria ligada à área da saúde em Ribeirão Preto. Dissertação (Mestrado em Economia). Universidade de São Paulo, São Paulo, SP, 2002.

TÖRNROOS, J. Terminating relationships in business networks? Reflections on business strategy. 20th Annual Conference on the Industrial Marketing and Purchasing (IMP), Copenhagen, Dinamarca, 20. Anais... Munich, Alemanha: IMP Group, 2004.

TRIGILIA, C. Social capital and local development. European Journal of Social Theory, v.4, n.4, p.427-442, 2001.

VAN DUJIN, M. A. J.; VERMUNT, J. K. What is special about social network analysis. Methodology, v.2, n.1, p.2-6, 2006.

VASSOLO, R. S.; WEISZ, N. O capital social das equipes empreendedoras nascentes. ERA - Revista de Administração de Empresas, v.44, n.2, p.26-37, 2004. 
VEDOVOTTO, N. M. Birigüi: a revolução começou pelos pés. São Paulo: Saga, 1996.

WALKER, G.; KOGUT, B. SHAN, W. Social capital, structural holes and the formation of an industry network. Organization Science, v.8, n.2, p.109-125, 1997.

WOOLCOCK, M. Social capital and economic development: toward a theoretical synthesis and policy framework. Theory and Society, v.27, n.2, p.151-208, 1998.

ZUCKER, L. G. The role of institutionalization in cultural persistence. American Sociological Review, v.42, n.5, p.726-743, 1977.

Institutional theories of organization. Annual Review of Sociology, v.13, p. 443-464, 1987. 